\title{
"This is My Story": Autobiography as Curriculum in High School Arts and Literature Programs
}

\author{
Kate Greenway \\ Independent Scholar
}

\begin{abstract}
"[Children] master their own story first, then tackle someone else's [1]." How do we intentionally place students at the centre of the curriculum? What is the value of incorporating the lived experience of all who share the classroom space? The imaginative act of telling one's story is tied to voice, and educators must help children find their voice, especially those who hitherto have been ignored. Sharing theory, practice and examples from my own teaching experience as a senior secondary school educator, and three different student projects involving autobiography as curriculum in arts and literature courses, I hope to demonstrate the value of such a practice of storytelling in its various incarnations. In all cases transformative learning takes place. Students are opened up to new perspectives and understandings, connect to others, engage in meaningful dialogue, and create open and safe spaces that value diversity, and the importance of all who enter the classroom.
\end{abstract}

\section{Introduction}

As an educator who specializes in English literature, creative writing and drama in the secondary panel, I have always believed in the power of inviting students' own lived experience into the classroom as a method of fostering social-emotional well-being. Curriculum does not have to be an ongoing quest for content, but rather a place for investigating the ways we live in the world, opening up spaces for discussion and reflection. Part of this investigation begins with thinking about how we frame knowledge.

In epistemological terms, what is knowledge and how is it acquired? Is knowledge an end in itself? For me, as for educator/researcher Maxine Greene, "knowledge is anything that helps us to know ourselves and the world in which we live" and it is acquired through interactions with others [2]. Knowledge is a vehicle for skill development and the evolution of our thinking, and education should allow knowledge to function as a way of helping students make meaning of their lives, not as a quest to memorize facts and acquire information. If students' own identity is nurtured and acknowledged, this enhances their ability to respond to others, to create empathy -- especially when a story offers a counter-narrative to the dominant -- and thus to celebrate differences and create communities. As
William Pinar quotes Greene, "education at its best is a process of teaching people to explore ideas about themselves and the world in which they live, to ask questions about the experience called living and to embrace ambiguity [3]." Part of learning to live with and embrace ambiguity is the recognition that all perspectives are contingent: we must understand that no one perspective is complete or authoritative. By investigating, questioning and celebrating the lives of those who participate in the classroom, we can say that we are developing the knowledge of our students in a curriculum that is no less purposeful than one that is merely content driven.

This concept of curriculum relates closely to theorist Madeleine Grumet's, who feels curriculum is not a set of facts, or a program of studies, but "the process of making sense with a group of people, of the systems that shape and organize the world" [4]. Curriculum theorist Janet Miller also argues that we are reconceptualizing ideas about what curriculum is, moving away from a linear development of content to "examining personal and political dimensions of educational experience [5]." This subverts traditional notions of curriculum as structured, progressing through stages of perceived essential knowledge, to pre-determined outcomes. For teachers then, it is necessary to design tasks that foster a conscious, deliberate and thoughtful search for understanding of the personal. To develop a sense of self, and that self in the world, to imagine possibilities beyond what one is currently exposed to and led to believe, and to respond to others' ideas about self and community, is a powerful form of agency.

I bring this understanding of curriculum to my everyday teaching practice, to the selection of my materials and approaches, and to my interactions with students. Specifically, I incorporate projects that bring the personal into the classroom, as in the three following examples drawn from three different secondary level courses. In my creative writing class we produce creative non-fiction iBook's sprung from multiple writing prompts that require students to consider what is relevant in their lives. They are tasked to move beyond diary, to tap into the universal that moves beyond self-reflection and invite the reader/listener into the punctum of truth. In my drama class, students produce a solo performance piece, given the simple instruction that in a performance time of ten minutes or less, they tell their life story and try to reveal "what makes you, you." Other than being personal and meaningful, 
there are no restrictions on format, structure, content, theatricality, or style. And in my "Studies in Literature" English course, as part of understanding the power and effect of rhetoric, students give their own Ted Talk on what they value. They are asked, "What is your truth? What advice would you give to your fellow students and those listening to you, as you explore the values and beliefs you hold dearest if it was the last time you could speak?" In all cases, the personal stories that emerge when students are allowed to call them forth mean a classroom where every member's experience is valued.

I would like to share how, in bridging theory and practice, in these three different arts and literary classes in my secondary school, I try to facilitate activities that lead to the production of these autobiographical works. In so doing I hope this may serve as a springboard for other educators when considering why and how to include student lived experience into their classroom.

\section{Considerations}

What might an educator need to take into account when considering bringing autobiography into the curriculum?

\subsection{Narrative Identity}

Humans construct stories to make meaning of our lives and who we are, combining the personal with the social. Stories give voice to tacitly held knowledge, beliefs and understandings, and help us position ourselves in the world. The self at it core is storied, and our narrative identity, that internalized life story, evolves and grows as we do. Researchers such as Clandinin and Connelly [6] and Jerome Bruner [7], have used narrative inquiry as a methodology, a field of studies and a way of representing research, to investigate how important it is to understand the open-endedness of our stories and perceived truths, how mutable they are when positioned against time, distance, re-telling, other participants' perspectives, cultural and historical milieu and other factors that, without examination, can freeze us into one version of truth and one understanding of the significance of a lived experience told from a single vantage point. Students sharing their stories can help each other uncover what may appear to be truths, which, in fact, may be assumptions or scripts performed without consciousness of alternatives or fallacies. In so doing, they may find the ability to re-conceptualize their actions, and visualize other futures and ways of being in the world.

\subsection{Plurality of Voice}

Mikhail Bakhtin's idea of polyphonic voices extends to communication and interaction in the classroom. Instead of understanding and privileging many voices as harmonizing into one cohesive, he extolled the importance of multi-voiced human communication, realizing that truth does not reside in a single person or idea, but more likely in a collective of individuals searching for truth through their interactions and dialogue [8]. Each voice remains distinct, while also influencing and being influenced by continuous interaction with others. Our diversity of background, language, social strata, belief systems, and so forth, means there is a multiplicity of viewpoints, coexistence of conflicting ideological positions, and competing discourse unmerged into a single perspective. By leveraging this, instead of ignoring it, we can begin to tap into the lived experience of those participating in our teaching and learning spaces.

Opposing viewpoints can bring contention, and without careful consideration, may lead to a combative environment. Conflict does not have to equate to confrontation in a classroom where connection and interpersonal relationships have been established. Rather it can allow students to engage in meaningful discussion, with serious emotional and cognitive investment in the subject at hand, without silencing contributions or harming self-esteem, and therefore engender new learning, develop empathy and tolerance, and empower them to make a difference.

\subsection{Identity Struggles}

In his theory of psychosocial development, psychologist Eric Erikson suggested that during adolescence one of the primary processes of ego development is fidelity and identity versus role confusion, or a sense of self and self-worth, and how that self fits into society [9]. Outside forces play a huge role in the formation of this personal identity, and there are many cultural and societal messages that work to undermine confidence in one's inherent worth. Messages about body image, gender identity, popularity, normality, etc., bombard young people every day, intensified by social media, that can effect shaming, trauma and isolation, the feeling of not fitting it and never being good enough. By allowing students to re-examine and revisit moments of their experience and how these have shaped their lives, it is possible for young people to reflect on their stories with greater self-compassion, and by sharing with others, in a supportive space, the sense of isolation and pressure to be someone one is not, can be counter-acted with feelings of dignity and self-worth. 


\subsection{Assumptions of Truth}

Janet Miller cautions that "many educators approach pedagogical and research uses of autobiography with an assumption that there are simple and transparent correspondences among dignity voice experience, memory" [5]. We must recognize that memory is imperfect, and understanding is often elusive. Life writing is the story of the self situated within a cultural and historical context, imbued with all the biases that such systems impose upon one's conscious or unconscious understanding of themselves, and of others. This may call for intervention and disruption of patterns of behaviour and belief that limit or impede understandings of self or others in compassionate and constructive ways.

Personal truth does not automatically equate with validity. An unproblemetized account of a life story, seemingly having a cause and effect, linear path without contradiction, may lead to a simplification of life experience. If we do not allow for contractions, incompletions and rethinking of narratives, choices and paths, the autobiography may prove simply a pastiche or placebo to explain how the past brought us into the present, and by extension, how we must approach our future. Students must interrogate assumptions, choices, and social, parental, institutional norms that may have influenced beliefs, choices and outcomes, with the hope of recognizing there may be alternate choices available to them. They must be open to other ways of existence that may not have been apparent, and realize the incompleteness and redefinability of their life possibilities. Further, they must know stories change over time. What is begun in adolescence evolves in adulthood and beyond - we never can truly know ourselves, especially as we are not isolated from family, community, workplace, and societal and cultural beliefs, which also change and shape how we are situated within larger stories. With all narratives, whether real or fictional, it is difficult say that they are "true." Stories, after all, are merely aesthetic creations containing selected events, ordered and prioritized, to explain and support the narrator's aim, and in transmission from the teller to the recipient, also influenced and interpreted by both persons, a further manipulation of 'fact.' Yet within this artistic structure lies an interesting paradox: "autobiographers cannot lie because anything they say, however mendacious, is the truth about themselves, whether they know it or not [10]." Such emotional truth may serve as an entry point for discussion and critical inquiry.

\section{Key Pedagogical Tools}

When employing autobiography in the curriculum, the instructional approach must keep the following in mind:

\subsection{Learner Centered Approach}

The student must have control over many aspects, such as what activities or prompts serve as inspiration for further development and which do not resonate with them, and over how s/he will employ the tools, prompts, skills and strategies worked on over the course of the project. They must have the ability to control what they share, how much, when, and with whom, in order to develop trust and selfconfidence. This privileging of student voice and self-direction is critical to success.

\subsection{Active Learning Strategies and Open- Ended Prompts}

The process is as important, if not more so, than the product. While the stories that emerge are individual in nature, the process is surprisingly collaborative and cyclical. There must be many opportunities for interaction with others, for working through deliberately ambiguous directions and prompts that require many attempts at interpretation or approach, for making connections, and for combining ideas taken from a range of activities over time.

\subsection{Teacher as Guide}

In these projects there is no one in command, who has the ability to designate what is 'correct' or the right way of completing a task. Teachers instead work alongside students as a guide not an authority figure, to encourage, offering suggestions, to point to areas where further thought, research or revision is needed. They may also find themselves as part of the writing community, sharing their own stories and thus fostering greater connections with their students.

\subsection{Reflective Practice}

Students must be taught how to pause, rethink, and revise their work, and more importantly, why and how. This goes beyond mere editing, and instead uses revision as its etymology truly suggests, as a relooking with fresh eyes at their creations and efforts at self-expression. Students are asked if rhetorical strategies are being incorporated, for example, why, and for what effect? Is their story clear to others, or are they skipping details and making assumptions? Students must also learn to give and receive specific feedback intended as critical support for 
improvement. They must learn how to listen to criticism, and how to incorporate what is useful. Finally, they must practise putting into words their understanding of the process and its outcomes, and what they might have gained from them.

\section{Outcomes}

What are the possibilities when a teacher invites autobiography into their classroom?

\subsection{The Arts as Self-Exploration and Expression}

Students may be unfamiliar with the arts as a means of effective communication that engages mind, body and spirit. The act of writing or creating art is a method of meaning-making, and exploring the self, allowing unformed or unconsciousness ideas to be brought to light. Art also disallows reductionism, by virtue of its ambiguity, its refusal of certainty and singularity, thus creating a mindset where one is constantly open to, and searching for, meaning in all its complexity, rather than simplicity - a virtue particularly important in this political climate of populism and ideological divide.

\subsection{Building the Capacity for Reflection}

Engagement with the creative process helps build understanding of the value of feedback, reflection, and reiteration. Students engage with each other and their teacher as co-creators, learning to appreciate input as helpful pathways for exploration and consideration for improvement. In giving and receiving feedback, and reworking versions of their stories, they also increase their own capacity for selfreflection.

\subsection{Enhancement of Student Voice}

Donald Graves theorizes that a sense of self is strengthened when writing from a first-person point of view, and fluency is increased when students feel they have ownership of their voices, selecting their own topics and searching for their own truths [11]. Using the self in memory as subject matter allows students to view themselves and their past from different angles, rather than from a fixed perspective. In such reworking and drafting as part of the process of composition, students may come to new understandings, especially about habits and patterns and beliefs in their life experience that may need rethinking. There will be many unanswered and unanswerable questions, but these may also trigger further investigation into half-exposed truths. Such personal discovery may foster greater resilience when confronting present and future challenges.

\subsection{Critical and Creative Thinking}

The ability to deal with purposeful ambiguity in turn enhances critical and creative thinking skills. At the core of creativity is the desire to express ourselves, and what more compelling vehicle to do so than telling our own stories? In order to achieve success, students think deeply about what they are going to share, why, and how. They must also work through a multi-faceted and layered approach to their final project, forcing greater complexity in their solutions.

\subsection{Motivation and Student Engagement}

Problematic for both teachers and students is the seemingly increasing lack of interest and engagement in many traditional methods, practices, subjects and assignments in school. By using a learner-centered approach with greater student selfdirection, students may be moved from a passive learning stance to an active one, fostering deeper learning. Perhaps for the first time, students using their own experiences can now claim a knowledge base in which they are experts. And when one is confident in one's own abilities, and this is met with an appropriately matched challenge, students will engage more easily. As well, the value we place on students' individual identities influences their commitment to the culture of the school and their learning in our classrooms. Motivation to learn is heightened with the ability to identify issues and causes that resonate with students, and that are relevant in their lives. Students may overcome barriers of disengagement and become more willing to learn. Because they care about the subject matter, and how it is presented, they also tend to inquire more deeply into techniques and skills that build their abilities to present their ideas cogently and effectively.

\subsection{Empowerment and Self-Esteem}

If students' experience is valued and respected, they see themselves reflected in the curriculum as worthy of study, and of having something important say: they become knowledgeable co-participants in the learning. Akin to the Reggio Emilia approach to classroom and curriculum, which exhorts environment as third teacher [12], the inclusion of student stories amplifies the idea of seeing themselves, their interests and their community represented, not just in a display of student work, or in the layout and design of the physical classroom, but in the intrinsic valuing of their own identity within the social environment. This, in turn, helps foster the development of self-esteem, a sense of belonging, and the students' belief in themselves and in their abilities as capable learners. 


\subsection{Personal Agency in a Culture of Caring}

In sharing their own stories, students may realize that their struggles are not necessarily unique, and that others may share parts of their challenges, setbacks and fears, and may have found coping mechanisms and methods of support. Student wellness is increased when communication, collaboration and relationship development are encouraged. This sense of personal agency within the collective community may help shape how students deal with transitions, turning points, stress and adversity in future.

\subsection{Fostering Community}

The sharing of stories encourages curiosity about other perspectives, and empathy. Thereby, students may find points of real connection to others in the classroom, people they may previously have not known or have ignored. In creating a safe space for dialogue, and a trusting environment, students may also find a place where they can feel comfortable to be their authentic selves. And the more students are exposed to ideas that differ from their own, yet still offer the connection to the person sitting beside them in class, the more it is possible for meaningful dialogue about difficult issues, fostering a strong, respectful community.

\section{Project Examples}

What follows is a small sample of the kinds of autobiographical projects I have incorporated into my curriculum, the process leading up to the assigning of the project, and observations on the outcomes.

\subsection{Creative Non-Fiction Books in "Writerscraft"}

In my creative writing class, we produce creative non-fiction iBook's sprung from multiple writing prompts that require students to consider what is relevant in their lives. They are tasked to move beyond diary, to tap into the universal that moves beyond self-reflection and invite the reader/listener into Roland Barthes' punctum of truth [13] - that wounding detail or accident which bruises. Students engage in many smaller journal writing exercises and skill building activities in the process. Some ask them to investigate sensory triggers to memories. Another focuses on how multiple perspectives and the passage of time may shift a story or our understanding of its significance. Open-ended prompts may ask them to write of a "bruise" they remember or develop their awareness of contradictions in "what they don't remember."
Throughout the process, there is ample time for sharing, peer feedback, reflection, and making connections between seemingly disparate writing activities.

Directions for the final project include "Don't be the hero" - and to try to make the story about more than yourself. Reach for a universal truth that you and your reader know or share. Tell me how you constructed your piece so that it is more than just an anecdote? Ask yourself, "What do I understand now about this story and about myself that I did not understand when I was living through it?" Move from "Micro to Macro" - Focus on a simple moment or moments. Then slowly move your reader out into bigger ideas that will give your piece importance and a broader appeal.

And "Show Don't Tell" - Maybe one of the most important ideas of all. Give your reader some credit in terms of their ability to imagine and for having spent time on the planet. We don't need to literally tell them what is happening every step of the way. Or as Emily Dickinson might say, "Tell all the truth but tell it slant [14]."

Writing pedagogy specialists such as Lucy Calkins [15] and Donald Graves [11] stress the importance of writing for students that is deeply rooted in personal experience. Calkins states that, "we cannot write well if we are afraid to let our individual voice stand out from other voices," and that, "writing allows us to hold our life in our hands and make something of it"[15]. Students writers in my course all invested themselves in the writing process and in the crafting of their final product, with explorations of bullying, parental pressure, homelessness, self-esteem, emerging sexuality, cultural norms, coping with death, and other topics that drew from their lives and needed to be articulated, not just as fodder for an assignment, but as a true expression of selfhood, and the self in the world. The "product" however, is not an end in itself.

Peer reviewers of the drafting process are asked to examine the specific techniques the author uses in order to structure and present their piece of creative non-fiction, and what the effects are. They note their understandings of the themes and messages being conveyed, and if there are connections, extensions or problems with what is being said. Authors are required to submit a creative insight reflection on their work, including discussing what they hope the audience will take away from their work, and how their truth-filled story might illuminate an audience's perceptions of their own world, in order to situate the personal within the public context. Oral feedback is given by the class after each author explains their motivation and inspiration for their writing and reads their piece to the class.

I see in these days' great nervousness in the authors before they share, and in every case, a sense of empowerment and satisfaction as they finish their 
presentations and participate in the discussions of their life story with the class. There is heightened anticipation in the classroom as a whole as they look forward to sharing in their classmates' experiences and find connections to their own. They might offer counterpoints to ideas brought up, or corroborations of what the author might have felt as an isolated or singular experience. Focus, attention, and participation are at maximum levels in the classroom. As one recent participant remarked in summary of her learning, "You are not better or worse than anyone - your voice matters just as much."

\subsection{Last Lecture Ted Talks in "Studies in Literature."}

As one of the elective English option for grade 12 students in the Ontario Ministry of Education curriculum, this course offers many opportunities to stretch beyond a traditional canon. Each year, as I begin, I pre-survey my incoming students as to their reading habits, learning preferences, favourite books, skills and knowledge desired to obtain, strengths and challenges, hopes for the course and so on, in order to tailor the year to their needs and interests. Specific texts and units come and go; rather I focus on the skills, habits of mind, and practices and processes of interpretation and uncovering meaning. However, one unit remains fixed - rhetoric - through which I specifically incorporate student autobiography and voice.

As a unit taught in the hopes of elevating student discourse, we focus on the art of effective writing, convincing argument, and eloquent delivery. We dig into many historic and contemporary models to provide us with mentor texts, to investigate how to effectively and efficiently make your point. We examine appeals, schemes and tropes, organizational strategies and logical fallacies. We listen to great orators, and to not so great ones, and compare their use of diction, delivery and logic. But where we spend the most time is on two autobiographical pieces that serve as springboards for the students' own writing: first is the preface to Bertrand Russell's autobiography, "What I have Lived For" [16]. As compact and astonishingly eloquent as a threeparagraph essay can be about what is important in life, my students are always amazed at what is packed into such a tiny space. And later we watch Randy Pausch's Last Lecture [17], the Ted Talk delivered to his students, wife and children with foreknowledge of imminent death, containing his poignant advice to about how to live a fulfilled life. Russell's preface discusses the difficulty of coming to certainty about one's ideals and experiences; Pausch's talk investigates how life even one sadly truncated, can be as beautiful and inspirational as you make it.
It is easy to see the assignment: students to deliver their own Last Lecture. I ask them, what is your truth? What advice would you give to those listening to you, as you explore the values and beliefs you hold dearest - if it was the last time you could speak? Students must include images drawings, personal photos or other visuals that also reinforce their ideas. And they must present publically - not just to our own class, but also to a wider audience, extending their voice to others, and taking them beyond the comfort of the everyday classroom.

As they begin creating their own pieces, the classroom becomes a laboratory. They brainstorm and mind map on their own and with peers. They rotate through timed protocols that allow them to pitch their ideas and then to listen for response and feedback. Each student has multiple chances to obtain the perspective and suggestions of others, while practising and refining their piece. As their teacher, I layer in structure, inviting them to include rhetorical schemes and tropes to enhance impact, and to make connections to other courses, to their own interests, to what they are reading or listening to, or experiencing in their world.

Last year, the Head and Assistant Head of school, among others, were invited to hear their presentations. After emotional reception, students debriefed their experience and the significance of the assignment to them. They spoke of the trust and mutual respect established in the classroom, and of their investment in the project, and its open-ended nature. One girl says she worked on the piece for weeks, only to rip it up and rewrite for three days straight right before presentation - because she felt she had not captured her heart. I saw reticent learners speak with pride and confidence - this is a subject, after all, that they know. No one is more the expert than they are. They delivered raw, emotional, erudite and simple pieces - all with dignity and passion.

We heard of being misunderstood and dismissed by teachers and peers, of going through depression, normative forces that squelched creativity and imagination, realizing that they could not be someone their parents or their culture expected them to be, even transitioning gender bravely and openly. What a wonder to be in the room with such articulate and genuine young people - who were allowed to speak their truth. In Maxine Greene's view, "the classroom situation most proactive of thoughtfulness and critical consciousness is the one in which teachers and learners find themselves conducting a kind of collaborative search, each from her or his lived experience" [2]. It appears that in this project, both in the creation and reception of the stories, such a search was engaged. 


\subsection{Autodrama in "Theatre Performance"}

In my drama class, their autobiographical assignment begins with viewing Amanda Marshall's music video "Everybody has a Story [18]." In it, she describes the assumptions we make about others without trying to see beyond them, and exhorts us to go beyond superficial conversations in order to explore our shared experience as part of the human condition. We then go through a series of writing prompts and paired discussions over the course of several classes to stimulate their thinking about their story. Questions posed include such things as what is your most powerful memory? What do you wish you could say to your parents, or to your friends? What are your biggest hopes? Or fears? What advice would you give to the world? And the final question is always, "What makes you, you?

Students must produce an autodrama. Autodramas are solo performances, where single actors play any and all parts, in order to tell a story about themselves. My students are given the simple instruction to "perform a one person show about your life in five to ten minutes." There are only three additional notes for guidance: it must be personal, it must be meaningful, and it must be theatrical. The directions are purposely ambiguous and students often struggle, used as they are to rubrics, lists of criteria, and parameters. Other than nudity, or open flame, I tell them if they ask, "Can I," or "Is it okay to?" the answer will be yes. There are no restrictions on format, structure, content, or style. They can make it as complex or as simple as they like. It can be serious, humourous, whimsical, or any combination.

Why am I telling my own story, they might ask? For one reason I say, here is a character you can absolutely relate to. If you are going to work on a play, you will have to use many parts of yourself. In creating a character, you have to find what is universal in their experience, what is being shared between their human condition and yours and, by extension, the audience's. Telling your own story allows a first step in thinking about your own participation in the human race, how you are unique, and how you connect to others while still being true to yourself.

As to the theatrical part - here is where craft and skill and the art of theatre come in. Rather than standing there and telling us, "Now this happened to me ..." they must find a metaphor or a frame for the presentation, and interesting presentational techniques. Lighting, projections, voice-overs, sound effects, personal photos and objects, the use of dance, song, music, mime, breaking the fourth wall, audience participation, manipulation of seating arrangements, site-specific theatre, and more are all techniques my students have employed to great effect.
For such a personal assignment, where students make themselves vulnerable, the atmosphere must be protective, and people have to trust each other. In other words, I tell them, what is said inside the classroom has to remain there. In this process the presentations may surprise even the participants often they are not prepared for the intensity of the experience or the feelings that may be brought up. We do not applaud at the end of presentation and there must be time for absorption and reflection.

What is central is intense debriefing following the presentations, in an open, safe environment, but this happens once all in the class have presented and there has been some time and space to reflect on what has transpired. Discussion often takes over a week, with participants willing and wanting to dive deeply into the ideas and emotions offered up in these stories. Because of the performative aspect of these autobiographies, the vulnerability of the creator is at its highest, but as with most activities, the greater the risk, the greater the reward. Autodrama is one of the most intense, but also, most transformative activity we undertake in the drama program, and one that alumni refer to as the project with most meaning in their high school career.

\section{References}

The results of including autobiography as curriculum are clear. The emotional and affective is connected to the intellect in this process, and students provide challenging and provocative stories that engage the whole person, and invite further discussion and reflection about the material presented. In these projects the academic is combined with creative expression, a mode that is often less frequently employed in senior high school courses, but the material is no less challenging. In the use of students' autobiographies as part of the curriculum they bring their own imagination and experience to an understanding of their lives, which is then demonstrated in creative and aesthetic platforms, and yet still create work that is scholarly, rigorous, and demonstrates their knowledge of issues, ideas, themes, and also of themselves and their world. Motivation to learn is high, especially as students see the relevance of the course material as it connects to their personal lives. Composing and sharing autobiographies allows for self-discovery but also for the creation of a product for an authentic audience. This is a rich performance task in every sense.

All of these projects are transformative every year, for individual students and for the class as a whole. I'll let the students speak for themselves in excerpts from their reflections over the years:

"I do not think I have ever felt the sense of accomplishment and satisfaction for any other project. This assignment was so personal and close to 
us that I wanted to truly make it the best I possibly could, and I can confidently say I do not think I could have put more into it.... I felt so fulfilled and pleased that I had accomplished this daunting task... When asked in a prompt "what fills me with joy' one of my answers was when I accomplish that which I did not think I could." That is exactly what this project caused me to do."

"I have never told anyone that story in detail, let alone ten people at once. I think it let off a load off my shoulders. I was able to look back on that night and realize exactly what I do not want to become. I was able to reflect and turn it into a positive situation for myself...after I was finished, I didn't even realize that I had just told my story. I was just speaking straight from my heart."

"How was it so difficult to come up with something about me - the one person I know best in the world? But then as I started developing an idea, I started trying to answer these questions: Why am I the way I am? Did I used to be different? Why did I change? Everything sort of just fell into place after that - I knew exactly what I wanted to say and how I wanted to say it."

"After this assignment I have noticed I have been thinking about life more. I have been reflecting back on events and talking to myself more about what makes me me... As I was watching everyone else's performance I could not help realize I was able to connect with everyone in one way or another. This assignment made me realize I had more in common with other people I did not know as much."

"So the day before my project I was rehearsing. I had everything sorted out perfectly for the next day's performance when I decided to throw my project out...And I'm very happy I did. I realized that this project was supposed to be about myself and not what other people wanted me to be."

"More than anything it allowed everyone a moment to look at themselves and tell each other who they think they are. I felt a deep camaraderie among our class through this project and think it reveals great trust when everyone can reveal such secrets, sometimes painful ones."

"I really enjoyed watching my peers. This project has allowed me to look beyond one's facade, and really understand who they are. Even with my closer friends, I made new realizations that I did not quite know."

"The fact that our class was able to share the private and profound moments is a tribute to the amount of trust that our teacher helped us to build as a group. I do not think anyone left feeling judged after their performance. This was an extremely eyeopening assignment for me."

"It was so personal and dear to our hearts. For once, I did not want to have the perfect assignment so I could get an amazing grade or pull up my average. For once my efforts had nothing to do with grades - I did this and poured so much of myself into this assignment for me, and for the proper presentation of my past that my life deserves."

"As mature classmates who have learned new things about one another, we will respect each other more and will be closer. Thank you for this opportunity of growth and development."

"The autodrama helped me learn something new. I am not very old, but I do have some wisdom to offer from my life experiences thus far. I didn't think I would be able to 'give' anything from it...Now after performing the autodrama I realized that I can. I have something to offer beyond any textbook. I have wisdom."

"Basically, I'm no longer afraid to let somebody see who I truly am."

Clearly such work has had a profound impact on the students who have engaged in creating, delivering and responding to their life experiences and the experiences of others. Sharing theory, practice and examples from three student projects involving autobiography as curriculum, I hope to have demonstrated the value of such a practice of storytelling in its various incarnations. "We need to compose and tell our stories as creative ways of growing in humanness," poet and academic Carl Leggo writes [19], and this is central to my own belief and practice. We all need to see our stories reflected, our experiences validated, as part of a diverse community rather than a homogenous one, and to be figures in the ground of our lives. This is important knowledge in the true sense of the word. Student autobiography deserves to hold a prominent place in our curriculum, and may others be inspired to find ways of including it in their practice.

\section{References}

[1] S. Ashton-Warner, Teacher, Simon and Schuster, New York, 1986.

[2] M. Greene, Releasing the Imagination: Essays on Education, the Arts, and Social Change, Jossey-Bass, San Francisco, 2000.

[3] W. F. Pinar, The Passionate Mind of Maxine Greene: I am...Not Yet, Routledge, Oxton, 1998.

[4] M. Grumet, "The Curriculum: What Are the Basics and Are We Teaching Them?" Thirteen Questions: Reframing Educations Conversations, 2nd Ed., Longman Publishing Group, New York, 1995.

[5] J. Miller, Sounds of Silence Breaking: Women Autobiography, Curriculum, Peter Lang Inc., New York, 2005.

[6] D.J. Clandinin and F. M. Connelly, Narrative Inquiry: Experience and Story in Qualitative Research, JosseyBass, San Francisco, 2000. 
[7] J. Bruner, Acts of Meaning, Harvard University Press, Cambridge, 1990.

[8] M. Bakhtin, Problems of Dostoevsky's Poetics (Theory and History of Literature Vol. 8), University of Minnesota, Minneapolis, 1984.

[9] E. H. Erickson, Childhood and Society, W.W. Norton and Co., 1950

[10] S. Smith and J. Watson, Reading Autobiography: A Guide for Interpreting Life Narrative, 2nd Ed., University of Minnesota Press, Minneapolis, 2010.

[11] D. H. Graves, Writing: Teachers and Children at Work, 20th Anniversary Ed., Heinemann, Boston, 2003.

[12] L. Malaguzzi, "History, Ideas, and Basic Philosophy: An Interview with Lella Gandini," The Hundred Languages of Children: The Reggio-Emilia Approach Advanced Reflections, 2nd Ed., Ablex Publishing, Westport, 1998.

[13] R. Barthes, Camera Lucida, Hill and Wang, New York, 1981.

[14] E. Dickinson, "Poem 1129," The Complete Poems of Emily Dickinson, Little Brown and Co., New York, 1976.

[15] L. Calkins, The Art of Teaching Writing, Heinemann, Boston, 1994.

[16] B. Russell, "What I Have Lived For," Bertrand Russell Autobiography, Routledge, London, 1975.

[17] R. Pausch Last Lecture: Really Achieving Your Childhood Dreams, Carnegie-Mellon, Pittsburgh, 2007.

[18] A. Marshall, "Everybody's Got a Story," Everybody's Got a Story, Sony Music, New York, 2001.

[19] C. Leggo and P. Sameshima, "Startling Stories: Fiction and Reality in Education Research," A Companion to Research in Education, Springer, New York, 2005. 